\title{
Case of pregnancy favorable outcome in a patient receiving hemodialysis therapy
}

\begin{abstract}
Pregnancy is the most important period in woman's life. The health of a mother and a baby depend on how comfortable and safe this period goes. However, pregnancy in patients with the end-stage chronic renal failure (ESCRF) receiving renal replacement therapy (RRT) by program hemodialysis (PHD) is associated with a high risk of complications at all stages of pregnancy development. A comprehensive approach to the treatment of such patients involves the interaction of Obstetricians and Gynecologists with Dialysis Department experts, adequate dialysis therapy in combination with pregnancy prolongation measures. This article represents a case of a successful pregnancy resolution in a patient receiving PHD lasting more than 22 years. We have explored the actual issues of dialysis therapy correction. We have described the problems of the woman's body preliminary sixmonth training, monitoring of the early diagnostics of pregnancy and further antenatal and obstetric care in critical situations by Caesarean section in 27-28 weeks pregnancy with a live male fetus.
\end{abstract}

Keywords: pregnancy, chronic program hemodialysis, end stage of chronic kidney failure
Volume 4 Issue 6 - 2017

\section{Putintseva AD,' Zhdanova IV,' Lavrinovich OE, ${ }^{2}$ Kuznetsov SV, ${ }^{2}$ Temirbulatov RR, ${ }^{3}$ Bezhenar VF, ${ }^{3}$ Leontieva NV ${ }^{4}$}

'Dialysis Department, Federal State Budgetary Institution, Russia ${ }^{2}$ Department of Gynecology, Federal State Budgetary Institution, Russia

${ }^{3}$ Department of Obstetrics, Gynecology and Neonatology; Clinic of Obstetrics and Gynecology, Russia

${ }^{4}$ Department of Internal Medicine and Nephrology of the Federal State Budget Educational Institution of Higher Professional Education "North-West State Medical University, Russia

\begin{abstract}
Correspondence: Anastasiia Putintseva, Dialysis Department, Federal State Budgetary Institution, All-Russian Center of Emergency and Radiation Medicine n.a.A.M.Nikiforov under the Ministry of the Russian Federation for Civil Defense, Emergencies and Elimination of Consequences of Natural Disasters (FGBUVTsERMn.a.A.M.Nikiforov, Clinic No. 2 of EMERCOM of Russia), Saint Petersburg 197374, 54 Optikov str., Saint Petersburg, Russia, Tel +7(98I)83I-34-14, Email putyablag@mail.ru
\end{abstract}

Received: April 28, 2017| Published: June 07, 2017
Abbreviations: ESCRF, end-stage chronic renal failure; RRT, renal replacement therapy; PHD, program hemodialysis; HCG, human chorionic gonadotropin; MBD, mineral and bone disorders; URR, urea reduction ratio; PCL, parietal-coccygeal length; NT, nuchal translucency; EPO, epoetin-alfa; PCD, protein-calorie deficiency; EMA, emergency medical aid; $\mathrm{CC}$, cervical canal; $\mathrm{CKD}$, chronic kidney disease

\section{Introduction}

Motherhood is neither more nor less than the state of the female body determined by child-bearing, child birth and breastfeeding, involving her into a new quality of existence. Medical supervision is important at every step, from diagnosis of pregnancy to delivery. It is known that early detection of pregnancy in patients with ESCRF treated with PHD is difficult, due to the initial increase in serum beta-chorionic human gonadotropin. ${ }^{1-3}$ The average frequency of conception in women of childbearing age is low and is in the range from $0.3 \%$ to $1.5 \%$ a year. ${ }^{3}$ At the same time, despite a high risk of perinatal mortality, skilled management of patients with ESCRF at all stages of pregnancy contributes to the successful delivery in $40 \%$ $-75 \%{ }^{4-15}$

\section{Clinical observation}

The patient P, born in 1977, was supervised for chronic glomerulonephritis with the outcome to ESRD. Since 1994, she has been receiving RRT by PHD3 times a week using the dialyzer lops 18 for 4 hours 30 minutes at a flow rate of $230 \mathrm{ml} / \mathrm{min}$ at the arteriovenous fistula of the right forearm. Composition of the dialysis solution: acetate (SW $449 \mathrm{~A}, 1+44)-\mathrm{Na}+139 \mathrm{mmol} / \mathrm{L}, \mathrm{K}+3.0$ $\mathrm{mmol} / \mathrm{L}, \mathrm{Ca}++1.5 \mathrm{mmol} / \mathrm{L}$, Glucose $1.0 \mathrm{~g} / \mathrm{L}, \mathrm{Mg}++0.5 \mathrm{mmol} / \mathrm{L}$, chlorine $107 \mathrm{mg} / \mathrm{L}, \mathrm{HCO} 3-36 \mathrm{mmol} / \mathrm{L}, \mathrm{CH} 3 \mathrm{COO}-3.0 \mathrm{mmol} / \mathrm{L}$; bicarbonate (Bic $8.4 \%$ ) - NaHCO3 $84.0 \mathrm{~g} / \mathrm{L}$. The past medical history features allotransplantation of a cadaveric kidney (1995), complicated by a cytomegalovirus infection and a crisis of rejection, repeated allotransplantation of a cadaveric kidney (ACK) in 1996. Among the illnesses she mentioned autoimmune thyroiditis, viral hepatitis B and C was recorded as a result of blood transfusion in 1994. Virus carrying is preserved. All previous pregnancies 2004, 2005, 2006 ended in induced abortionas the request of a woman.

In February 2013 the desired unplanned pregnancy was diagnosed at a gestational age of $6 / 7$ weeks and was confirmed by laboratory monitoring of the level of human chorionic gonadotropin (HCG). At the time of pregnancy diagnosis anemia, mineral and bone disorders (MBD), liver performance indicators, dyselectrolytemia has not been detected: hemoglobin 121-116 g/L, total serum calcium $2.3 \mathrm{mmol} / \mathrm{L}$, inorganic phosphorus $1.6 \mathrm{mmol} / \mathrm{L}$, free parathormone $97.4 \mathrm{pg} / \mathrm{ml}$, AST 10E/L, ALT 20E/L, total bilirubin $10.5 \mathrm{mmol} / \mathrm{L}$, potassium 4.7 $\mathrm{mmol} / \mathrm{L}$, sodium $136 \mathrm{mmol}$, albumin $36.8 \mathrm{~g} / \mathrm{L}$. Urea and creatinine levels in serum reached $567 \mathrm{mcmol} / \mathrm{L}$ and $1.11 \mathrm{mmol} / \mathrm{L}$ respectively. The dialysis dose was adequate; regime of dialysis did not change $(\mathrm{Kt} / \mathrm{V}$ Dialysis Dose (Daugirdas) $=1.39$; Urea Reduction Ratio $(\mathrm{URR})=0.66) \cdot{ }^{16-18}$ Anticoagulation was $6000 \mathrm{U}$ bolus type using low molecular weight heparin. The patient received routine therapy with calcium supplementation at a dose of 3 grams per day, L-thyroxin 25 $\mathrm{mkg} / \mathrm{day}$. Since the establishment of the fact of pregnancy, therapywas strengthened by appointment by vitamin E $400 \mathrm{mg} /$ day, Folio-1 tablet/ day, Utrogectan $300 \mathrm{mg}$ /day per vaginum, Ketosteril 3 pills x 3 times/ day. 
At the gestational age of $9 / 10$ weeks the frequency and duration of dialysis session was increased up to 6 times a week for 4 hours. Hemodiafiltration was not carried out due to patient's poor tolerability. Initial "dry" weight was $67 \mathrm{~kg}$. According to the rate of weight gain of a healthy woman during pregnancy, the patient was corrected for the "dry" weight in200-400 ml weekly. At the gestational age of 12 weeks the first ultrasound screening was performed. According to fetometry: the parietal-coccygeal length $(\mathrm{PCL})=59 \mathrm{~mm}$, nuchal translucency $(\mathrm{NT})=1.4 \mathrm{~mm}$. Clinical and laboratory monitoring of beta-HCG: $24920 \mathrm{IU} / \mathrm{L}$ (normal is from 20,000 to $90,000 \mathrm{IU} / \mathrm{L}$ or $13.4-128.5 \mathrm{ng} /$ $\mathrm{ml}$ ) - in the normal range. Pregnancy-associated plasma protein-A = $3.57 \mathrm{mU} / \mathrm{ml}(0.03-100 \mathrm{mU} / \mathrm{ml})$. Herpesvirus type IV to the DNA copy 1.6x104 HHV6/ml, herpes zoster anti-VZV IgG to $1,696 \mathrm{mIU} / \mathrm{mL}$, anti-phospholipin antibodies (IgG - $12.6 \mathrm{U} / \mathrm{ml}(0-4.5), \operatorname{IgM}-8.2 \mathrm{U} /$ $\mathrm{ml}(0-4.5))$ raising was recorded, as well as a positive result for the presence of antibodies to rubella and toxoplasmosis. Indicators of hepatitis $\mathrm{B}$ and $\mathrm{C}$ virus were within the normal range.

At the gestational age of 12 weeksa decrease in the hemoglobin level to $104 \mathrm{~g} / \mathrm{L}$ has already been revealed. The therapy was enhanced with the addition of Epoetin-alfa (EPO) in a dose of $6000 \mathrm{U} /$ week in combination with oral iron preparations (Ferrous sulphate+Ascorbic acid $200 \mathrm{mg}$ /day). From 14 to 16 weeks of pregnancy, despite attempts to correct anemia due to an increase in the dose of EPO and a change in the oral intake of iron for intravenous administration, the hemoglobin value was steadily declining. At the gestational age of 16 weeks the EPO dose was already $16.000 \mathrm{U} /$ week, the hemoglobin level was $83 \mathrm{~g} / \mathrm{L}$. On the 17 th week of pregnancy, taking into account the increase in ALT to 71-88 E/L, 5 heptral infusions of $400 \mathrm{mg}$ daily were performed. Recommended strict adherence to dietary recommendations (diet number 5). Intravenous administration of iron preparations is replaced by oral. Progressing hypoalbuminemia (27.9 $\mathrm{g} / \mathrm{L}$ ) determined the tactics of correction of protein-calorie deficiency (PCD). Ketosteril was cancelled and a super protein was prescribed for 1 spoon 3 times/day. The ultrasound pelvic investigation at the gestation of 18 weeks showed the increase in amniotic fluid. The "dry" weight additions were stopped.

At the 21st week of gestation, the patient started having a yellowish-pink discharge in combination with a painful condition in the lower abdomen. According to the results of pelvic ultrasound monitoring an opening of the internal os, fetal bladders prolapsing to the cervix at $2.5 \mathrm{~cm}$ were diagnosed. In the uterus cavity, 1 fetus was detected in cephalic presentation, with a heart rate of 151 beats/ min. Due to the high risk of preterm delivery inside the emergency medical aid (EMA) vehicle, the patient was delivered to a hospital where she was diagnosed with premature discharge of amniotic fluid, spontaneous abortion at 21 weeks and $3 / 7$ gestation. According to the analysis of morpho-functional state of the placenta, acute placental insufficiency, immature placenta, focal purulent chorio-deciduitis were diagnosed. The genetic analysis of the fetus was not carried out. Anemia persisted -hemoglobin 85 g/L, PCD - albumin 26-23 $\mathrm{g} / \mathrm{L}$. After 7 days of hospitalization the patient was transferred to the Department of Gynecology of the All-Russian Center of Emergency and Radiation Medicine named after A.M. Nikiforov clinic No. 2 of the EMERCOM of Russia. Dialysis is returned to the original regime: 3 times a week for 4 hours 30 minutes, the antibiotic therapy was continued (Sultamicillin $1.5 \mathrm{~g}$ /day I.V. dripper No. 5), EPO therapy in a dose of $12.000 \mathrm{U} /$ week in combination with iron supplementation (Ferric III hydroxide sacharose complex 100mg x 2 times/week). PCD was corrected by receiving 9 doses of albumin $(20 \% 100 \mathrm{ml}$ № 9 x 3 times/week).
Over the next year the target hemoglobin level was reached, and therefore, the EPO therapy was cancelled. A psychologist repeatedly consulted the patient. On an outpatient basis, the patient was supervised by a gynaecologist with diagnose "Menstrual disorder, dysmenorrhea type". Ovarian dysfunction" (E28 at ICD-10). In 2015, at the patient's request, a comprehensive survey for preconception preparation was initiated. The dialysis dose was adequate; dialysis regime was not changed (Kt/V Dialysis Dose (Daugirdas) - 1.25; Urea Reduction Ratio (URR) - 0.68). ${ }^{16-18}$ Anticoagulation was $6000 \mathrm{U}$ bolus type using low molecular weight heparin. "Dry" weight $=66.0$ $\mathrm{kg}$. Clinical laboratory data: MBD - total serum calcium $2.2 \mathrm{mmol} / \mathrm{L}$, inorganic phosphorus $2.4 \mathrm{mmol} / \mathrm{L}$, free PTH $500 \mathrm{pg} / \mathrm{ml}$, small dyselectrolytemia - potassium $5.3 \mathrm{mmol} / \mathrm{L}$, sodium $133.4 \mathrm{mmol} / \mathrm{L}$. Liver function indicators remained within normal limits - AST 25 $\mathrm{U} / \mathrm{L}$, ALT $29 \mathrm{U} / \mathrm{L}$, total bilirubin $11.6 \mathrm{mmol} / \mathrm{L}$; PCD not found - total protein $67 \mathrm{~g} / \mathrm{L}$, serum albumin $39 \mathrm{~g} / \mathrm{L}$.

Thyroid hormones - in the normal range. Assessment of hormonal activity of the ovaries did not reveal pathology: lactation hormone $305 \mathrm{mIU} / \mathrm{L}$, estradiol - $285 \mathrm{pmol} / \mathrm{L}$, luteinizing hormone - $19.6 \mathrm{IU} / \mathrm{L}$ (1.1-11.6), follicle stimulating hormone (FSH) - 8.2 IU/L (2.8-11.3), oncocytology smears - without atypia, minimum number of leucocytes (up to 5 in the field of view) in a smear for flora, mixed flora, STDs not found. According to ultrasound imaging of the lower pelvis: at the time of the study, the endometrium corresponded to the second phase of the MC, with the thickness of $7.0-8.0 \mathrm{~mm}$. Signs of diffuse changes in the myometrium, endocervical cysts. Comprehensive treatment at that time included calcium supplements at a dose of 3 grams per day, cinacalcet $30 \mathrm{mg} /$ day, sevelamer $800 \mathrm{mg}$ 4-6 pills/day, L-thyroxine $25 \mathrm{mkg} /$ day, Ketosteril 9 pills/day. Planned pregravid therapy included dydrogesterone on 16-25 days of the menstrual cycle monthly $10 \mathrm{mg}$ x 2 times/day, "Femibion 1","Time Factor" vitamins during 3 months.

In order to prevent miscarriage and premature delivery the treatment was supplemented with dehydroepiandrosterone of 1 capsule every other day during 3 months. At the beginning of October 2015 the patient reported a delay in the planned menses for 7 days. According to the results of laboratory testing of the HCG level early pregnancy was diagnosed $(\mathrm{HCG}=2012 \mathrm{mIU} / \mathrm{mL}$ ). Correction of the dialysis and planned treatment was performed immediately: frequency and duration of dialysis sessions increased to 26 hours per week (4 hours and 30 minutes x 6 times a week). In order to prevent the development of hydramnios, the increase of the "dry" weight was not been performed. Sevelamer and cinacalcet therapy was canceled, started the taking of calcium citrate (Calcium citrate 1000mg + Magnesium citrate $500 \mathrm{mg} / \mathrm{Solgar} / \mathrm{USA}$ ) at 1 pill/day. The level of hemoglobin was within $120 \mathrm{~g} / \mathrm{L}$. Anticipating-worsening anemia and development of fetal hypoxia, EPO therapy was started from 3000 U/every 10 days in combination with oral iron (Ferric III hydroxide sacharose complex 100mg x 2 times/week). Docosahexaenoic acid taking was initiated (Omegamama 2 pills $x 3$ times/day).

During the subsequent week the HCG level was monitored three times to confirm the progression of pregnancy $(05.10 .15-8173$ $\mathrm{mIU} / \mathrm{mL}, \quad 08.10 .2015-27442 \mathrm{mIU} / \mathrm{ml}, 12.10$. 2015-62441 $\mathrm{mIU} /$ $\mathrm{ml})$. Ultrasound pelvic investigation in the area of the uterus cavity diagnosed 1 ovum $13 \times 10 \mathrm{~mm}$ containing 1 fetus of $4 \mathrm{~mm}$ diameter, retrochorial hematoma. Gynecological examination with ultrasound pelvic was conducted 1 time every 10 days. The therapy was reviewed: dydrogesterone $10 \mathrm{mg}$ x 3 times a day, progesterone 200 mg x 2 times per day, Femibion 1 pill/day. With increasing frequency and duration of dialysis sessions the patient's condition worsened after 2 hours from the beginning of dialysis. Negative dynamics in the 
form of increasing in heart rate up to $90-110 / \mathrm{min}$ and breathing acts till 19-20/min, anxiety was observed. Potassium level $-3.7 \mathrm{mmol} / \mathrm{L}$. Given the lack of effect of diet therapy (raisins, dry apricots, grapes, bananas, tomato juice, etc.) solutions of potassium and magnesium asparaginate (Panangin) were added to the treatment $10 \mathrm{ml}$ to $100 \mathrm{ml}$ Sol. $\mathrm{NaCl} 0.9 \%$ I.V. dripper. As a result, the patient's condition improved significantly.

On the 5 th/6th week of pregnancy, hemoglobin decreased to 114 $\mathrm{g} / \mathrm{L}$ and ferritin rose to $1134 \mathrm{mcg} / \mathrm{L}$. The dose of EPO was increased to $3.000 \mathrm{U} /$ week and the oral iron is reduced to $100 \mathrm{mg} /$ day. It should be noted that the leucocytosis detected at this time $-10.3 \times 10^{\wedge} 9 / \mathrm{L}$ - was maintained throughout the entire pregnancy. The ultrasonic monitoring at this stage did not reveal any signs of retrochorial hematoma. At the gestational age of 12 weeks one fetus was diagnosed. No rough congenital malformations and sonographic markers of chromosomal aberrations were found. The heartbeat was rhythmic, heart rate was 166 beats/min. According to fetometry: Parietal-coccygeal length $=52 \mathrm{~mm}$ (Snijders RJM), head circumference $=60 \mathrm{~mm}$ (Hadlock), hip thickness $=5 \mathrm{~mm}$ (Demidov), abdominal circumference $=$ $55 \mathrm{~mm}$ (Hadlock), RTA $=1.9 \mathrm{~mm}$, visualization of the nasal bones to be determined. Fetus dimensions correspond to 11-12 weeks of pregnancy. The ductus venosus PI $=1.1$, the tricuspid valve was in the normal range. Amniotic fluid was in the normal range. Chorionic villi was located on the rear surface of the uterine wall. The length of the cervical canal (CC) was $37 \mathrm{~mm}$. The internal os was not expanded. Myometrium had homogeneous structure, the nodes were not visible.

At the 14th week of gestation in connection with a progressive anemia - hemoglobin $105 \mathrm{~g} / \mathrm{L}$ - the dose of EPO is increased to 6000 U/week. Also was diagnosed with cholestasis of pregnancy - AST 40 U/L, ALT 91 U/L. Hepatoprotective therapy included Heptral infusion at $400 \mathrm{mg}$ I.V. dripper No. 5, with subsequent transition to Essentiale $600 \mathrm{mg}$ at 2 capsules $\times 2$ times/day, therapy of keto-aminoacids canceled and started with super protein at a dose of 3 spoons/day. Femibion-1 replaced in to Femibion-2 in dose of 1 tabl/day. Oral pharynx staphylococcal infection (staphylococcus aureus) has been identified. For the purpose of sanitation of the oral and nasal cavities, an oil solution of Chlorophyllin, Stomatofit and Derinat was used. Oral pharynx and nasal test inoculation did not include pathological microflora growth further. At the 16th week of gestation anemia increased - hemoglobin $97 \mathrm{~g} / \mathrm{L}$ and cholestasis - AST $49 \mathrm{U} / \mathrm{L}$, ALT $151 \mathrm{U} / \mathrm{L}$. Another correction of drug therapy included: increased dose of EPO 12000 U/week and Progesterone up to 200mg x 3 times/day and vitamins (Omegamama) was canceled.

At 17th week gestation during a follow-up pelvic ultrasound monitoring the uterine tonus was normal, fetal movement remained active. Attention was paid to the dynamic shortening of the cervix by $6 \mathrm{~mm}$. Negative dynamics manifested itself within two weeks: 36.0 $\rightarrow 30.9 \mathrm{~mm}$ in combination with the opening of the upper third of the cervical canal to $6.0 \mathrm{~mm}$. From 18th till 22th week's gestation the patient was being treated in the department of gynecology at the AllRussian Center of Emergency and Radiation Medicine. The motion behaviour was limited to II - bed rest. ${ }^{7}$ At 23 week of gestation given the high risk of preterm delivery the patient was again admitted to the obstetric clinic with a diagnosis of "Ongoing pregnancy week 23/24. Insuficiencia istmicocervical. Hydramnios". Gradual shortening of the cervix in combination with the expansion of the internal os.

In order to prevent the syndrome of respiratory distress, the fetus performed 4 intramuscular injections of dexamethasone $12 \mathrm{mg}$ at intervals of 12 hours. The second course was held 2 weeks later. At
27/28 weeks gestation - 03.03.2016 - in connection with the beginning of premature birth, cesarean section in the lower uterine segment was performed. We extracted a live aborted fetus male weighing 970 grams, length $35 \mathrm{~cm}$, and autonomous respiration. Apgar score: 5/6 points. No postpartum complications were noted. The patient was discharged on the seventh day after birth in a satisfactory condition with the recommendations following the diagnosis: Pregnancy 2728 weeks. Insuficiencia istmicocervical. Hydramnios. Premature delivery. Chronic glomerulonephritis. Terminal chronic kidney disease. The child was transferred to Children's City Hospital No. 1 for further observation and treatment. At the age of four months the boy was discharged in satisfactory condition with a weight of $3 \mathrm{~kg}$ 600 grams under the supervision of a paediatrician, a neurologist, a pulmonologist at the place of residence.

\section{Discussion}

The case features qualified care and treatment in a specialized hemodialysis department of the EMERCOM of Russia in St. Petersburg for a patient aged 39 years with chronic kidney disease (CKD) and pregnancy, starting with a preconception preparation. Chronic glomerulonephritis with the outcome to CKD was diagnosed since the patient was $17 \mathrm{y} / \mathrm{o}$. The first pregnancy in the patient was diagnosed at the age of 27 years against the backdrop of a 10-year period of dialysis therapy, which contributed to the normalization of the most important functions of the body, including reproductive. This is evidenced by the fact of overcoming infertility (medical abortions $2004,2005,2006$, late spontaneous abortion at the 21 week period). At the time of the beginning of the pregravid preparation, the duration of the prolonged dialysis therapy was 22 years. Since 1994 hemodialysis treatment of the patient hasn't changed. At the present time we have obtained the results of many comparative studies of the quality of PHD and HDF therapy. ${ }^{17,19}$ Despite the results obtained worldwide, in our dialysis department patients receive hemodiafiltration therapy strictly according to indications. ${ }^{19}$

In 2013 with the onset of pregnancy the patient was transferred to hemodiafiltration therapy. We changed the dialysis membrane from low flux to high flux and increased bloodflow from 230 to $300 \mathrm{ml} /$ min led to a sharp deterioration in the patient's condition. This was manifested by destabilization of hemodynamics in the form of jumps in bloodpressure during the dialysis procedure and an extension of the recovery period after the end of the procedure. Given the deterioration in the quality of life of the patient using hemodiafiltration, inorder to preserve and prolong the pregnancy, our attempt stotre at hemodiafiltration were stopped and did not recur. It is known that the prognosis of pregnancy outcome for the mother and fetus with CKD

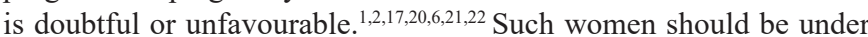
the supervision throughout the pregnancy. According to the Ministry of Health and Social Security of the Russian Federation order No. 731 from 2007, CKD of any ethiology (N 18. 9) is a medical indication for an induced termination of pregnancy. The level of blood serum creatinine prior to conception for any diagnosis in patients with CKD should not exceed $200 \mathrm{mmol} / \mathrm{L}(1.8 \mathrm{mg} / \mathrm{dL})$. The progressive increase in serum creatinine in any period of pregnancy requires immediate termination.

The patient totally refused to interrupt the pregnancy, which occurred after the preconception preparation. In the process of dynamic monitoring, adequate correction of both dialysis and planned drug therapy was conducted. ${ }^{23,24,25,26,22} \mathrm{Kt} / \mathrm{V}$ level of the pregnant patient with daily dialysis session was not less than 1.2 during all period for the whole observation period. We suppose that the patient has poor 
URR because of the large fluid losses during dialysis session (3.54.0 liter spersession). ${ }^{1,2,17,20,18,19}$ Changes of the blood volume during ultrafiltration by suprasonic technique of the blood line were not used. The patient's mode of ultrafiltration was constant ultrafiltration. Before the pregnancy the patient received iron preparations as needed. Hemoglobin level was within the target level $(120 \mathrm{~g} / \mathrm{L})$. Epoetin alfa was not used. This clinical case confirms the high frequency of pregnancy complications, starting already at 12 weeks: cholestasis of pregnancy, anaemia. In 2013, during pregnancy, the patient received irontherapy, but inview of the appearance and increase of cholestasis in combination with chronic hepatitisinfection, on there commendation of a gynecologist, many drugs, including ironpreparations, were canceled. Also, epoetin alfa therapy was not started ontime, which led to anemia, which arose and grows indynamics. In 2015, during these conddesired pregnancy, we took into account the available initial experience. ${ }^{27-31}$

In 2016 starting at 16-17 weeks gestation cervical insufficiency is formed. Closure of the cervix reduces the incidence of preterm delivery, up to 33 weeks, according to the references. In this case, a contraindication to surgical treatment of the cervical insufficiency is the disease that is a contraindication to the preservation of pregnancy, in particular, CKD. Continued conservative therapy preserves pregnancy at 23-24 weeks in the third level obstetric clinic allowed to prolong for 5 more weeks, prevent the respiratory distress syndrome of fetus using glucocorticoids. The optimum method of delivery was caesarean section. As a result the mother and the child were discharged in satisfactory condition after 7 days and 4 months respectively.

\section{References}

In obstetrical practice, cases of refusal to interrupt pregnancy with women with severe somatic pathology, which is a contraindication to pregnancy, are not uncommon because of the high risk of maternal and perinatal morbidity and mortality. The description of this clinical case makes us think about reviewing the views and tactics of administering patients of childbearing age with ESRD to PGD and to focus on creating teams of like-minded doctors aware of their responsibility for fulfilling the most cherished dream of every woman - the birth of a child. The analysis of this case allowed us to formulate the main points in the work with this category of patients. First, the desire of a woman to become a mother persists despite the prohibitions and warnings of dialysis physicians. In the case of a woman's conscious desire, pregnancy planning and mandatory pregravid preparation for conception are necessary. It includes the following:

i. Examination and observation by a gynaecologist in conjunction with possible correction of therapy

ii. Comprehensive laboratory and instrumental examination (ECG, ECHO-KG, chest X-ray of both partners, ultrasound of the abdominal cavity and pelvis, urine culture in the presence of residual renal function, sowing from the throat and nasal cavity).

iii. Consultation of the dentist.

iv. Therapeutic and/or surgical treatment of all available chronic foci of infection.

v. Secondly, early monitoring of the fact of pregnancy, namely the control of serum HCG with a delay in planned menses for 2-3 days or more and the performance of ultrasound. Control of ultrasound of the pelvis should be performed at least once every 10 days throughout the pregnancy, while paying special attention to the size of the cervix and cervical canal.
Thirdly, in the case of early pregnancy diagnosis, a transition to daily hemodialysis of a total duration of at least 24 hours per week is necessary. It is preferable to conduct hemodialysis therapy in combination with hemodiafiltration with its satisfactory tolerability. Do not forget that the minimum content of potassium in the dialysis solution should be at least $4.0 \mathrm{mmol} / 1$. According to the indications during the dialysis session, it is possible to perform infusion therapy with the use of potassium preparations. In order to correct diselectrolithy, it is necessary to prescribe combined therapy with calcium and magnesium preparations. Particular attention should be given to early initiation of therapy with erythropoietin for the prevention and treatment of anemia. In our case, EPO therapy is started at a haemoglobin level of $120 \mathrm{~g} / \mathrm{l}$.

\section{Conclusion}

I would like to note the fact that from 16 to 18 weeks, in order to maintain and prolong pregnancy, strict restriction of physical activity of a woman is necessary, by mandatory stay in a specialized obstetricgynaecological hospital.

\section{References}

1. Nephrology. Guidelines for doctors in 2 volumes. Vol.2/Edited by I A Tareeva/RAMS -M: Medicine, 1995. p. 203-218.

2. Nephrology. Textbook for postgraduate education/edited by EM Shilova (2 $2^{\text {nd }}$ edn,) updated. - M: GEOTAR - Medif, 2008. p. 486-497.

3. Goldenberg RL, Tamura T. Pre Pregnancy weight and pregnancy outcome. JAMA. 1996;1127-1128.

4. Bespalova AV, Bondarenko TW, Kozlovskaya NL. Successful completion of pregnancy in a patient with end-stage kidney disease, under more than 10 years treatment using program hemodialysis. Nephrology and Dialysis. 2014;16(4):48-487.

5. Bagon JA, Vernaeve H, De Muylder X. Pregnancy and dialysis. Am J Kidney Dis. 1998;31:756.

6. Chakhtoura Z, Meunier M, Caby J. Gynecologic follow up of 129 women on dialysis and after kidney transplantation: A retrospective cohort study. European Journal of Obstetrics Gynecology and Reproductive Biology. 2005;187:1-5.

7. Giatras I, Levy DP, Malone FD. Pregnancy during dialysis: case report and management guidelines. Nephrol Dial Transplant. 1998;13(12): 3266-3272.

8. Holley JL, Reddy SS. Pregnancy in dialysis patients: a review of outcomes, complications, and management. NCBI. US National Library of Medicine. National Institute of Health. Semin Dial. 2003;16(5):384-388.

9. Hou S. Pregnancy in chronic renal insufficiency and end-stage renal disease. Am J Kidney Dis. 1999;33(2):235-252.

10. Hou S. Pregnancy in Women on Dialysis: Is Success a Matter of Time? Clin J Am Soc Nephrol. 2008;3:312-313.

11. Hou SH. Frequency and outcome of pregnancy in women on dialysis. Am J Kidney Dis. 1994;23(1):60-63.

12. Jungers $\mathrm{P}$, Chauveau D. Pregnancy in renal disease. Kidney Int. 1997;52:871.

13. Okundaye I, Abrinko P, Hou S. Registry of pregnancy in dialysis patients. Am J Kidney Dis. 1998;31(5):766-773.

14. Piccoli GB, Conijn A, Consiglio V. Pregnancy in dialysis patients: is the evidence strong enough to lead us to change our counseling policy? Clin J Am Soc Nephrol. 2010;5(1):62-71. 
15. Phyllis August, John Vella. Pregnancy in women with underlying renal disease. Walter Kluwer Health. 2013.

16. Guide to dialysis. John T Daugirdas, Peter J Blake, Todd S Ing Translation from English/Edited by A Yu Denisov OOO "Triada" "Publishing House, Russia, 2003. p. 683-696.

17. Mann H, Ernst E, Gladziwa U. Changes in blood volume during dialysis are dependent upon the rate and amount of ultrafiltrate. ASAIO Trans. 1989;35(3):250-252.

18. Rocco MV, Cheung AK, Greene T. The HEMO Study: applicability and generalizability. Nephrol Dial Transplant. 2005;20(2):278-284.

19. Maduell F, Moreso F, Pons M. High-Efficiency Postdilution Online Hemodiafiltration Reduces All-Cause Mortality in Hemodialysis Patients. J Am Soc Nephrol. 2013;24(3):487-497.

20. Cunningham FG, Cox SM, Harstad TW. Chronic renal disease and pregnancy outcome. Am J Obstet Gynecol. 1990;163(2):453-459.

21. Krupa FG, Faltin D, Cecatti JG. Predictors of preterm birth. Int Gynaecol Obstet. 2006;94(1):5-11.

22. Leitich H, Brumbauer M, Kaider A. Cervical length and dilation of the internal as detected by vaginal ultrasonography as markers for preterm delivery: a systematic review. Am J Obstet Gynecol. 1999;181(6):1465-1472.

23. Barua M, Hladunewich M,Keunen J. Successful pregnancies on nocturnal home hemodialysis. Clin J Am Soc Nephrol. 2008;3(2):392-396.
24. Demirci C, Sezis Demirci M. Frequency and outcomes of pregnancy on nocturnal home haemodialysis. Turkish Nephrology, Dialysis and Transplantation Journal. 2017.

25. Gadallah MF, Ahmad B, Karubian F. Pregnancy in patients on chronic ambulatory peritoneal dialysis. Am J Kidney Dis. 1992;20(4):407-410.

26. Hou SH. Pregnancy in women on haemodialysis and peritoneal dialysis. Baillieres Clin Obstet Gynaecol. 1994;8(2):481-500.

27. Brief description of the standard treatment regimens. Medical-Enc.ru 2007-2016.

28. Lim TSC, Shanmuganathan M, Wong I. Successful multigravid pregnancy in a 42-year-old patient on continuous ambulatory peritoneal dialysis and a review of the literature. BMC Nephrol. 2017;18:108.

29. Toma H, Tanabe K, Tokumoto T. Pregnancy in women receiving renal dialysis or transplantation in Japan: a nationwide survey. Nephrol Dial Transplant. 1999;14(6):1511-1516.

30. THE Actim ${ }^{\mathrm{TM}}$ Partus versus the TLIIQ system as rapid response tests to aid in diagnosing preterm labor in symptomatic women. Institute of Health Economics: Preterm Labor in Symptomatic women.

31. Schettler VJ, Schulz EG, Hagenah GC. Successful completion of pregnancy using apheresis and a balanced dose of coagulation factors in the presence of high thrombophilia and Lp(a) levels in a woman with two previous abortion. Clin Kidney J. 2014;(2014) 7:497-498. 